\title{
Aspectos gerais sobre catarata: uma revisão narrativa
}

\author{
Cataract overview: a narrative review \\ Descripción general de cataratas: una revisión narrativa
}

Amanda Brandão Lopes ${ }^{1 *}$, Laís Assunção Vilefort ${ }^{1}$, Ana Cecilia Lima Gonçalves ${ }^{1}$, Rebecca Guerra Murta Leste ${ }^{2}$, Laura Machado Barbosa Junqueira², Nicole de Souza Bueno ${ }^{3}$, Gabriela Bortoni Faria $^{3}$, Bárbara Bersan de Andrade ${ }^{4}$, Janaína Laila Rodrigues Castilho ${ }^{5}$, Lucas lemini Valério ${ }^{3}$.

\section{RESUMO}

Objetivo: Ampliar os conhecimentos sobre a catarata. Revisão bibliográfica: A catarata é uma doença resultante da opacificação do cristalino ocular que pode afetar crianças, adultos e idosos, sendo mais comum em pessoas de idade avançada. A doença dificulta a penetração da luz no olho e, consequentemente, a formação da imagem na retina, muitas vezes ocasionando sérios problemas para as pessoas acometidas no desenvolvimento de suas atividades diárias. Na presença de alterações visuais, 0 paciente deverá procurar o médico oftalmologista para realização de exames específicos. $O$ tratamento para catarata pode variar desde clínico, apenas com uso de lentes corretivas ou poderá ser cirúrgico. Considerações finais: A catarata é um problema de visão que pode cursar com amaurose, comprometendo de forma significativa a qualidade de vida do indivíduo que possui a doença. Portanto, na presença de sintomas visuais sugestivos o paciente deverá procurar um oftalmologista para realização do diagnóstico e estabelecimento de um plano terapêutico de acordo com as necessidades do caso.

Palavras-chave: Catarata, Cristalino, Amaurose, Doenças oftalmológicas.

\begin{abstract}
Objective: Expand knowledge about cataracts. Bibliography review: Cataract is a disease resulting from opacification of the ocular lens that can affect children, adults and the elderly, being more common in elderly people. The disease hinders the penetration of light into the eye and consequently the formation of an image on the retina, often causing serious problems for people affected in the development of their daily activities. In the presence of visual changes, the patient should seek an ophthalmologist for specific exams. The treatment for cataracts can vary from clinical, only using corrective lenses or it can be surgical. Final considerations: Cataract is a vision problem that can occur with amaurosis, significantly compromising the quality of life of the individual who has the disease. Therefore, in the presence of suggestive visual symptoms, the patient should seek an ophthalmologist for diagnosis and establishment of a therapeutic plan according to the needs of the case.
\end{abstract}

Keywords: Cataract, Crystalline, Amaurosis, Ophthalmic diseases.

\section{RESUMEN}

Objetivo: Ampliar el conocimiento sobre cataratas. Revisión bibliográfica: La catarata es una enfermedad resultante de la opacificación del cristalino ocular que puede afectar a niños, adultos y ancianos, siendo más común en personas mayores. La enfermedad dificulta la penetración de la luz en el ojo y en consecuencia la formación de una imagen en la retina, provocando a menudo graves problemas a las personas afecta das en el desarrollo de sus actividades diarias. En presencia de cambios visuales, el paciente debe buscar un oftalmólogo para exámenes específicos. El tratamiento de las cataratas puede variar desde el clínico, con

\footnotetext{
${ }^{1}$ Faculdade de Minas de Belo Horizonte (FAMINAS-BH), Belo Horizonte - MG.

*E-mail: amandabrandaolopes@gmail.com

2 Universidade José do Rosário Vellano (UNIFENAS-BH), Belo Horizonte - MG.

${ }^{3}$ Faculdade de Ciências Médicas e da Saúde (SUPREMA), Juiz de Fora - MG.

${ }^{4}$ Centro Universitário de Valença (UNIFAA), Valença - RJ.

${ }^{5}$ Pontifícia Universidade Católica de Minas Gerais (PUC-MINAS), Betim - MG.
} 
solo usar lentes correctivos o puede ser quirúrgico. Consideraciones finales: La catarata es un problema de visión que puede ocurrir con la amaurosis, comprometiendo significativamente la calidad de vida del individuo que padece la enfermedad. Por tanto, ante la presencia de síntomas visuales sugerentes, el paciente debe acudir a un oftalmólogo para el diagnóstico y establecimiento de un plan terapéutico acorde a las necesidades del caso.

Palabras clave: Catarata, Cristalino, Amaurosis, Enfermedades oftálmicas.

\section{INTRODUÇÃO}

A catarata é a principal causa mundial de cegueira tratável. Dentre os 45 milhões de cegos no mundo, $40 \%$ são devido à catarata. Nessa doença ocorre a opacificação ou a turvação do cristalino ou de sua cápsula, o que impede a passagem da luz para a retina do olho. Pode afetar tanto idosos como adultos e até mesmo crianças (SHEELADEVI S, et al., 2016).

A luz é focalizada na retina através de uma lente biconvexa chamada de cristalino, uma estrutura transparente, com um comprimento axial de cerca de $4 \mathrm{~mm}$ e um diâmetro aproximado de $10 \mathrm{~mm}$. Consiste em fibras derivadas do epitélio do cristalino, com a presença de uma cápsula fina ao seu redor e fibras zonulares que permitem a acomodação em conjunto com o corpo ciliar (SHEELADEVI S, et al., 2016). A catarata pode ocorrer de forma unilateral ou bilateral e possui grau de gravidade variável. Possui uma progressão gradual sendo inicialmente assintomática, mas à medida que evolui, especialmente após a quarta ou quinta década de vida, a catarata amadurece, o que torna o cristalino completamente opaco à luz e acaba por interferir nas atividades diárias (QURESHI MH e STEEL DHW, 2020).

Para manter a sua transparência, o cristalino possui uma via de microcirculação conduzida por canais de sódio que faz com que chegue nutrientes às fibras mais profundas através de um fluxo extracelular. $O$ fluxo de saída intracelular, por sua vez, é estabelecido através de junções comunicantes e tem como objetivo a remoção de possíveis resíduos. Ele também atua como um filtro ultravioleta que serve para a proteção da retina contra a radiação. A chamada presbiopia ocorre quando há o endurecimento do cristalino com o avançar da idade (NIZAMI AA e GULANI AC., 2021).

A catarata é subdividida em quatro classes distintas: congênita, de aparecimento precoce, de aparecimento tardio e adquirida, que inclui todas as outras formas de catarata, inclusive a que está relacionada à idade (DUBOIS VDJP e BASTAWROUS A, 2017). Ela poderá ser classificada como nuclear, cortical ou subcapsular, de acordo com a sua localização e denominada de incipiente, madura ou hipermadura de acordo com o grau de opacidade (GIGNAC DB, et al.,2020).

Existem algumas opções de tratamento que incluem correção com óculos refrativos ou cirurgia. Os óculos são eficazes apenas em estágios iniciais. Se a catarata estiver madura o suficiente para interferir nas atividades cotidianas a cirurgia passa a ser o tratamento recomendado. A intervenção cirúrgica é considerada o tratamento mais eficaz para a doença, independentemente da sua etiologia (MOSHIRFAR M, et al., 2021).

Esta revisão teve por objetivo fornecer uma ampla abordagem a respeito da catarata, incluindo pontos como epidemiologia, etiologia, fisiopatologia, manifestações clínicas, diagnóstico, tratamento, complicações e prognóstico da doença.

\section{REVISÃO BIBLIOGRÁFICA}

\section{Epidemiologia da catarata}

De acordo com estudos, a catarata é mais comum na raça branca americana, onde possui uma prevalência que oscila de 17 a 18 acometidos a cada 100 pessoas. Estima-se, dessa forma, que cerca de $10 \%$ da população norte-americana seja afetada pela doença e que esta prevalência pode aumentar em até $50 \%$ na faixa etária entre os 65 e 74 anos, enquanto em pessoas acima de 75 anos sua incidência pode aumentar ainda mais, chegando a 75\% (SHEELADEVI S, et al., 2016). 
Em 2013, existiam mais de 22 milhões de pessoas com catarata nos Estados Unidos. Os negros englobam a segunda etnia mais afetada pela doença, com uma taxa de prevalência de cerca de $13 \%$, seguidos pelos hispânicos com uma taxa de prevalência de aproximadamente $12 \%$. As mulheres são ligeiramente mais afetadas quando comparada aos homens, com uma incidência média de $26 \%$ e $22,6 \%$ respectivamente (GIGNAC DB, et al.,2020).

\section{Etiologia da catarata}

Apesar desta doença ainda não ter as suas causas muito bem definidas existem estudos epidemiológicos que revelam uma forte associação entre a catarata e a idade avançada. Porém, existem diversos fatores já identificados que podem ser responsáveis pelo desenvolvimento da doença. Existem algumas circunstâncias durante a gestação que podem levar à catarata congênita, como por exemplo a presença de infecções como a rubéola e a toxoplasmose, uma má nutrição materna e uma oxigenação ineficiente decorrente de uma hemorragia placentária. Já a catarata senil, tipo mais comum de catarata, pode ocorrer em alguns idosos, devido ao próprio envelhecimento (GIGNAC DB, et al.,2020; LIU Y e CAI Q, 2020; MOSHIRFAR M, et al., 2021).

A catarata também pode estar relacionada a uma lesão ocular do tipo traumática e esta é a causa mais comum de catarata unilateral em adultos jovens. Uma causa rara dessa doença é o choque elétrico, que causa opacificação do tipo branco leitosa difusa no cristalino. Quando ocorre intensa exposição à radiação ultravioleta, a cápsula anterior do cristalino pode sofrer um processo de esfoliação, levando à catarata. No tratamento de tumor ocular e durante certas intervenções cardiológicas podem ser necessárias a utilização de radiação ionizante que pode gerar opacidades subcapsulares posteriores. Lesões químicas também podem levar ao desenvolvimento dessa doença (SHARMA B, et al., 2020).

Algumas doenças sistêmicas, endocrinometabólicas e renais podem estar associadas ao aparecimento da catarata. Dentre as sistêmicas é possível citar: dermatite atópica, distrofia miotônica e neurofibromatose do tipo 2. Hipoparatireoidismo, diabetes mellitus, galactosemia, cretinismo e hipocalcemia são exemplos das doenças endocrinometabólicas (KELKAR A, et al., 2018).

Além disso, existem algumas doenças oculares primárias que, quando presentes, podem predispor o indivíduo à catarata, sendo elas: grau elevado de miopia, uveíte anterior crônica, pseudoexfoliação, distrofias hereditárias e fechamento de ângulo congestivo agudo. Algumas drogas, como os inibidores de anticolinesterase e os corticosteroides, podem causar opacidades subcapsulares anterior e posterior, respectivamente. A opacidade do cristalino pode ser facilitada pela má nutrição, com uma dieta deficiente em antioxidantes e vitaminas. O alcoolismo e o tabagismo também podem ser etiologias importantes da catarata (SINGH K, et al., 2017).

\section{Fisiopatologia da catarata}

O cristalino é uma estrutura transparente composta por fibras de células epiteliais modificadas inseridas em uma estrutura membranosa chamada de cápsula do cristalino. Sua composição consiste em duas partes principais: o córtex e o núcleo. O córtex se localiza na parte mais superficial e nele contém fibras mais jovens. O núcleo, por sua vez, está na parte mais profunda, contendo fibras mais antigas (DUBOIS VDJP e BASTAWROUS A, 2017).

Acredita-se que esta doença quando relacionada à idade ocorre devido ao dano oxidativo gerado ao cristalino e esse tipo pode ser subdividido anatomicamente em nuclear, cortical e subcapsular posterior. A catarata propriamente dita ocorre devido à perda de transparência do cristalino e devido a muitos processos degenerativos que desnaturam e coagulam as proteínas presentes em suas fibras por diferentes mecanismos, sendo eles: metaplasia fibrosa do epitélio do cristalino, originando a catarata subcapsular; distúrbios que ocorrem em qualquer nível de crescimento do cristalino, correspondendo a catarata congênita; deposição de certos pigmentos, ocasionando a catarata nuclear e hidratação cortical entre as fibras do cristalino, o que resulta em catarata cortical. Todos esses processos levam à formação de uma lente opaca atrás da pupila, o que torna extremamente difícil a penetração da luz no olho (SHORSTEIN NH e MYERS WG, 2020). 
As cataratas nucleares são as mais comuns, com uma incidência aproximada de $13,1 \%$. Com o avançar da idade, novas fibras são adicionadas ao cristalino, o que acaba por comprimir o núcleo, levando a uma esclerose nuclear. A catarata cortical, por sua vez, é a segunda mais comum, com uma incidência de $8,2 \%$ e é o tipo que mais requer intervenção cirúrgica. Normalmente elas se apresentam ao exame como opacidades dentro do córtex conhecidas como raios corticais. A opacificação no córtex posterior leva à opacidade posterior do cristalino, que é a menos comum, com incidência aproximada de $3,4 \%$ (LIM JC, et al., 2020).

\section{Mecanismos biomoleculares envolvidos na catarata}

A opacidade do cristalino assim como a dispersão da podem esta associados a um acúmulo significativo de proteínas de alto peso molecular nesta região. Mais de $90 \%$ das proteínas solúveis presentes no cristalino são constituídas do empacotamento ordenado de curto alcance, o que é importante para obter e manter a transparência da lente. O cristalino pode ser separado em regiões ricas e regiões pobres em proteínas por uma variedade de agressões físicas ou bioquímicas. Essas proteínas podem formar cristais, permanecer em solução ou formar agregados insolúveis, podendo resultar em dispersão da luz (SANTANA A e WAISWO M, 2011).

As mutações no cristalino quando são suficientes para causar agregação proteica resultam, normalmente, em catarata congênita. Porém, quando essas alterações apenas aumentam a suscetibilidade a agressões ambientais, como hiperglicemia, luz ou danos oxidativos, estão mais associadas à catarata relacionada à idade. A herança da catarata congênita é comumente mendeliana com alta penetrância, enquanto a herança da catarata relacionada à idade tende a ser multifatorial, com fatores ambientais influenciando o fenótipo e com probabilidade de múltiplos genes. Isso os torna menos suscetíveis ao estudo bioquímico e genético significativamente (MOSHIRFAR M, et al., 2021).

As cataratas do tipo congênitas podem ser também heterogêneas do ponto de vista genético. Podem ser gerados padrões de cataratas semelhantes em decorrência de diferentes mutações em um único gene. Sendo assim, as morfologias das cataratas do tipo altamente variáveis existentes dentro de algumas famílias sugerem diferentes fenótipos derivados de uma mesma mutação em um único gene. A catarata congênita está, atualmente, associada a mais de 25 genes em diferentes. Cataratas de várias morfologias já foram associadas à mutações em genes distintos, que codificam as principais proteínas citoplasmáticas do cristalino humano, incluindo genes que codificam proteínas estruturais do citoesqueleto, conexinas, cristalinas, aquaporinas, fator de transcrição homeodomínio pareado fator de transcrição de choque térmico e fibrossarcoma musculoaponeurótico aviário (SANTANA A e WAISWO M, 2011).

\section{Sinais e sintomas da catarata}

As manifestações clínicas dessa doença englobam: diplopia ou poliopia, o que significa visão dupla e visão múltipla, respectivamente, sendo que a formação dupla ou múltipla da imagem se deve a inúmeras refrações através de áreas claras entre as opacidades; sensibilidade ao brilho, especialmente faróis de automóveis e luz solar; diminuição da acuidade visual ou "embaçamento" da visão que pode ocorrer de maneira gradual e indolor, podendo ser unilateral ou bilateral; perturbação no reconhecimento das cores, gerando um aspecto de desbotamento ou amarelamento dos objetos e maior frequência de troca de óculos refrativos, pois conforme a catarata amadurece, uma pessoa pode visitar seu oftalmologista com mais frequência para ajustes das lentes corretivas (MONTERO MG, et al., 2019).

Os achados encontrados pelo oftalmologista no exame ocular do paciente podem variar a depender da parte da lente acometida. $\mathrm{Na}$ catarata cortical podem ser vistas: opacidade em forma de cunha com áreas claras de matéria cristalina principalmente presentes na periferia; opacidade em forma de cunha bem desenvolvida; opacidade avançada com lentes acinzentadas, córtex claro e sombra da íris; achados do estágio imaturo, mas com lente edemaciada devido ao acúmulo de líquido tornando a câmara anterior rasa; todo o córtex opaco com ausência de sombra da íris e saco de líquido leitoso com núcleo de lente presente na parte inferior devido à liquefação do córtex sem sombra da íris e uma câmara anterior rasa (KELKAR A, et al., 2018). 
Nos casos de catarata nuclear, por sua vez, podem ser visualizados no exame: lente marrom-escura ou preta com sombra de íris e ausência de visão do fundo devido à opacidade escura no centro. Em doenças sistêmicas pré-existentes também podem ser encontrados alguns achados específicos, como por exemplo: o diabetes mellitus pode gerar opacidades corticais clássicas em "floco de neve"; na distrofia miotônica pode ocorrer a catarata cortical da "árvore de natal" que posteriormente evolui para opacidades corticais e subcapsulares em forma de cunha, semelhantes a uma estrela em conformação; em pacientes com dermatite atópica podem surgir placas subcapsulares anteriores densas em forma de escudo e na neurofibromatose tipo 2, o paciente pode desenvolver opacidades mistas, que podem ser subcapsular, capsular ou cortical (MONTERO MG, et al., 2019).

\section{Diagnóstico da catarata}

Ao avaliar um paciente portador de catarata, deve-se ir por uma série de etapas. O primeiro passo para o seu diagnóstico envolve a escuta ativa da história atual informada pelo paciente, que inclui queixas principalmente de sensação de visão embaçada, nublada ou enevoada; redução global da acuidade visual; alteração na visão das cores e sensibilidade maior à luz. O segundo passo baseia-se na coleta de dados sobre a história oftálmica pregressa, como a presença de doenças prévias, o uso de lentes corretivas e cirurgias oculares prévias, assim como a investigação de outras doenças sistêmicas que sejam capazes de desencadear ou agravar os sintomas e o uso de medicações feita pelo paciente. Alguns sinais objetivos que podem ser encontrados no exame oftalmológico de rotina são: perda da acuidade visual e alteração da transparência do cristalino na biomicroscopia do segmento anterior em midríase (NIZAMI AA e GULANI AC., 2021).

Para a avaliação da acuidade visual é necessário a realização de um exame oftalmológico mais abrangente. Ela pode ser avaliada através do gráfico de Snellen que serve para identificar a gravidade da doença e as suas limitações causadas nas atividades cotidianas. Deve ser feita uma avaliação da refração, uma vez que este é um fator extremamente importante para planejar o tratamento da doença. Pode ser realizado o teste de cobertura, verificando se há uma visão deficiente causada por catarata podendo ser essa uma razão para um estrabismo divergente (LIU Y e CAI Q, 2020).

É importante a avaliação da resposta pupilar com o objetivo de verificar a forma da pupila, as vias aferentes e eferentes e, possíveis alterações pupilares. $O$ exame anexial, que se trata de um exame completo, por sua vez, é necessário para excluir qualquer patologia anexial, como por exemplo, blefarite, dacriocistite, lagoftalmo, conjuntivite crônica, ectrópio, entrópio e anormalidades do filme lacrimal. A presença dessas condições pode predispor à endoftalmite, o que torna o diagnóstico e otimização destes necessários para tratar catarata com maior sucesso (SUN H, et al., 2019).

Durante a avaliação da córnea é importante se esta é capaz de lidar com o trauma operatório. Deve ser realizado o exame da câmara anterior, pois uma câmara anterior rasa pode tornar a cirurgia de catarata extremamente difícil. A avaliação das lentes oculares, quantificando a porção da lente envolvida, é um fator importante para planejar a técnica cirúrgica. E por fim, o exame de fundo de olho não pode faltar, porque qualquer patologia do fundo do olho pode ser um fator importante para determinar o resultado visual após a cirurgia (NIZAMI AA e GULANI AC., 2021).

Existem algumas outras investigações oftalmológicas que podem auxiliar no manejo dessa doença, sendo elas: teste de câmara escura com oftalmoscopia direta e indireta; avaliação da pressão intraocular, realizada para descartar glaucoma; fundoscopia para descartar qualquer patologia vítrea ou retiniana; avaliação da retina periférica, testando a projeção de luz em todos os quadrantes; biometria para colocação de lente intraocular durante a cirurgia; teste de função macular como teste de papelão; teste de bastão de Maddox; eletrorretinogramafoveal; teste de fotoestresse; interferometria a laser; ultrassonografia recomendada para verificar 0 descolamento da retina ou qualquer patologia vítrea; entre outros (BRAAKHUIS AJ, et al., 2019).

Como exemplo de diagnósticos diferenciais da catarata podem ser citados o glaucoma, a degeneração macular, a retinopatia diabética, os erros de refração, a atrofia óptica e retinitepigmentosa e as distrofias e degenerações da córnea (LIU Y e CAI Q, 2020). 


\section{Tratamento da catarata}

A escolha do tratamento pode ser influenciada pelo grau de opacidade e se ele é ou não suficiente para causar dificuldade na realização das atividades diárias. Pode variar entre tratamento clínico o cirúrgico. 0 tratamento clínico é indicado quando a acuidade visual é 6/24 ou melhor e pode ser realizada a dilatação pupilar com fenilefrina $2,5 \%$ ou o uso de óculos refrativos em casos de embaçamento da visão ou diplopia. Ciclopentolato e atropina também podem ser medicações úteis. Atualmente existem alguns colírios que estão sendo testados para tratar a doença, que podem dissolver a catarata (NADERI K, et al., 2020).

A cirurgia para sua correção é indicada quando a acuidade visual é pior que 6/24 ou quando há indicação médica em que a catarata está afetando adversamente a saúde ocular, como nos casos de descolamento de retina, glaucoma facolítico e glaucoma facomórfico. Dependendo da queixa do paciente e da gravidade da doença, o cirurgião pode optar por um dos procedimentos cirúrgicos a seguir: irrigação e aspiração da lente, irrigação e aspiração da lente com implantação de Lentes Intraoculares (LIO) ou aspiração de irrigação da lente, vitrectomia anterior e capsulotomia posterior primária (DO DV, et al., 2018).

O único tratamento curativo dessa doença é o cirúrgico, em que ocorre a substituição do cristalino opaco por uma LIO. A cirurgia para sua correção está indicada sempre que a qualidade de vida do portador da catarata esteja comprometida, isto é, sempre que há limitações nas atividades cotidianas (SILVA SRD, et al., 2016).

A cirurgia é considerada curativa uma vez que consegue eliminar a catarata e, refrativa, devido à possibilidade de correção do vício de refração preexistente. Os seus resultados podem sofrer influência de alguns fatores como presença de comorbidades e idade. Com relação à técnica, a facoemulsificação possui, na grande maioria dos casos, resultados visuais melhores quando comparados à técnica extracapsular. Apesar dos resultados visuais da catarata congênita terem melhorado com a evolução da tecnologia, eles são mais difíceis de serem avaliados devido às características próprias desta doença, em especial ao tratamento da ambliopia, que pode ser atenuada ou evitada com estimulação visual precoce (DUBOIS VDJP e BASTAWROUS A, 2017).

As opções de tratamento para a catarata senil são: tratamento apenas clínico, realizado para melhorar o conforto do paciente, uma vez que nenhum tratamento médico é eficaz depois que a catarata amadurece e; cirúrgico, quando a catarata madura tem um núcleo muito rígido. Neste caso, um dos seguintes métodos é usado para extrair o cristalino: através de extração extracapsular de catarata, extração de catarata intracapsular ou facoemulsificação, modificação da extração extracapsular de catarata com menos astigmatismo e recuperação visual precoce ou facólise a laser, sendo este último um avanço recente ainda em teste (GRZYBOWSKI A, et al., 2019).

Para a realização do procedimento cirúrgico é necessário a abordagem de algumas condições clínicas do paciente, como Infarto Agudo do Miocárdio (IAM), infecção respiratória, controle do diabetes mellitus e da Hipertensão Arterial Sistêmica (HAS), angina, Artrite Reumatóide (AR), epilepsia, úlceras de membros inferiores, doença de Parkinson e hepatite viral (LEFFLER CT, et al., 2020).

\section{Complicações da catarata}

A catarata pode causar diversas complicações e elas podem estar associadas à outra doença ou à própria cirurgia, podendo ocorrer durante o procedimento ou após. Dentre as complicações estão os subtipos de glaucoma, subluxação do cristalino, hemorragia expulsiva, irite, amaurose, queimadura da córnea, ruptura da cápsula posterior, descolamento da retina, queda do núcleo no vítreo, prolapso da íris, infecções como endoftalmite ou panoftalmite, disfotopsia, ptose, mau posicionamento das lentes intraoculares, edema macular cistóide, espessamento capsular posterior e maior opacificação (LING JD e BELL NP, 2018).

\section{Prognóstico da catarata}

O seu prognóstico é influenciado por diversos fatores, como por exemplo: a idade, o tipo de catarata, o grau de deficiência visual, se há envolvimento unilateral ou bilateral do olho, o tempo e o modo de intervenção e se há presença de outra doença sistêmica. Na grande maioria dos casos, a visão é 
restaurada pela cirurgia de forma muito eficaz, possuindo um prognóstico excelente em cerca de 70 a $80 \%$ dos casos (MOHAMMADPOUR M, et al., 2019).

Se as instruções pós-operatórias e a forma de usar as medicações recomendados pelo oftalmologista forem seguidas rigorosamente, a maior parte dos pacientes apresenta excelentes resultados após 0 procedimento cirúrgico. Um exame oftalmológico de rotina é aconselhado para que possa ser detectado qualquer desenvolvimento de catarata no outro olho. Após sua remoção cirúrgica muitos pacientes com uma LIO monofocal podem precisar de óculos refrativos para atingir uma acuidade visual melhor (SILVA SRD, et al., 2016).

\section{CONSIDERAÇÕES FINAIS}

A catarata é uma doença ocular de etiologia multifatorial que causa opacidade do cristalino e impede a penetração adequada da luz no olho, podendo afetar crianças, adultos e idosos. As queixas mais frequentes dos pacientes acometidos são sensação de embaçamento da visão e redução da acuidade visual. 0 diagnóstico é feito pelo oftalmologista, o qual também irá planejar o melhor tratamento a depender do tipo de catarata e do seu estágio de evolução. O tratamento poderá ser clínico, apenas com o uso de lentes corretivas e colírios ou cirúrgico, sendo a cirurgia o único tratamento definitivo para doença. Este estudo oferece uma ampla abordagem sobre a catarata proporcionando maior conhecimento para profissionais médicos e não médicos, informando sobre características gerais e tratamento da doença.

\section{REFERÊNCIAS}

1. BRAAKHUIS AJ, et al. Nutritional Strategies to Prevent Lens Cataract: Current Status and Future Strategies. Nutrients, 2019; 11(5): 1186.

2. DO DV, et al. Surgery for postvitrectomy cataract. Cochrane Database of Systematic Review, 2018; 2018(1): CD006366.

3. DUBOIS VDJP, BASTAWROUS A. N-acetylcarnosine (NAC) drops for age-related cataract. Cochrane Database of Systematic Reviews, 2017; 1(2): CD009493.

4. GIGNAC DB, et al. Recent developments in the management of congenital cataract. Annals Translational Medicine, 2020; 8(22): 1545.

5. KELKAR A, et al. Cataract surgery in diabetes mellitus: A systematic review. Indian Journal of Ophthalmology, 2018; 66(10): 1401-1410.

6. GRZYBOWSKI A, et al. Diabetes and Phacoemulsification Cataract Surgery: Difficulties, Risks and Potential Complications. Journal of Clinical Medicina, 2019; 8(5): 716.

7. LEFFLER CT, et al. The history of cataract surgery: from couching to phacoemulsification. Annals of Translational Medicine, 2020; 8(22): 1551.

8. LIM JC, et al. Vitamin C and the Lens: New Insights into Delaying the Onset of Cataract. Nutrients, 2020; $12(10): 3142$.

9. LING JD, BELL NP. Role of Cataract Surgery in the Management of Glaucoma. International Ophthalmology Clinical, 2018; 58(3): 87-100.

10. LIU Y, CAI Q. Does Cataract Surgery Improve the Progression of Age-Related Macular Degeneration? A Meta-Analysis. Journal of Ophthalmology, 2020; 2020: 7863987.

11. MOHAMMADPOUR M, et al. Updates on managements of pediatric cataract. Journal of Current Ophthalmology, 2019; 31(2): 118-126.

12. MONTERO MG, et al. Binocular vision alterations after refractive and cataract surgery: a review. Acta Ophthalmologica, 2019; 97(2): e145-e155.

13. MOSHIRFAR M, et al. Cataract Surgery. StatPearls, 2021; 1-7.

14. NADERI K, et al. Cataract surgery and dry eye disease: A review. European Journal of Ophthalmology, 2020; 30(5): 840855.

15. NIZAMI AA, GULANI AC. Cataract. Treasure Island (FL): StatPearls Publishing, 2021; 1-5.

16. QURESHI MH, STEEL DHW. Retinal detachment following cataract phacoemulsification-a review of the literature. The Scientific Journal of The Royal College of Ophthalmologists, 2020; 34(4): 616-631.

17. SANTANA A, WAISWO M. The genetic and molecular basis of congenital cataract. Arquivos Brasileiros de Oftalmologia, 2011; 74(2): 136-42.

18. SHARMA B, et al. Techniques of anterior capsulotomy in cataract surgery. Indian Journal of Ophthalmology, 2019; 67(4): $450-460$.

19. SHEELADEVI S, et al. Global prevalence of childhood cataract: a systematic review. The Scientific Journal of The Royal College of Ophthalmologists, 2016; 30(9): 1160-1169.

20. SHORSTEIN NH, MYERS WG. Dropfree Approaches for Cataract Surgery. Current Opinion in Ophthalmology, 2020; 31(1): 67-73.

21. SILVA SRD, et al. Multifocal versus monofocal intraocular lenses after cataract extraction. Cochrane Database Systematic Reviews, 2016; 2016(12): CD003169.

22. SINGH K, et al. Review of manual small-incision cataract surgery. Indian Journal of Ophthalmology, 2017; 65(12): 12811288.

23. SUN H, et al. Chapter 14Femtosecond-Laser-Assisted Cataract Surgery (FLACS). High Resolution Imaging in Microscopy and Ophthalmology: New Frontiers in Biomedical Optics, 2019; 1(2):1-7. 